\title{
Does preoperative heparin increase the postoperative bleeding risk in women undergoing prosthetic breast implant surgery? A review of the data from a single institution
}

\author{
Sharon E Monsivais MD, Kendall R Roehl MD, Raman C Mahabir MD MSc
}

SE Monsivais, KR Roehl, RC Mahabir. Does preoperative heparin increase the postoperative bleeding risk in women undergoing prosthetic breast implant surgery? A review of the data from a single institution. Plast Surg 2015;23(3):165-166.

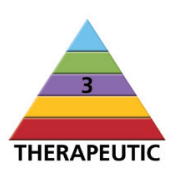

BACKGROUND: In 2008, the authors' institution adopted a policy requiring that all patients, regardless of preoperative risk, receive both sequential compression devices and a single preoperative subcutaneous 5000 unit injection of heparin. A previously published 12 -year review at this same institution before this policy demonstrated a $1.5 \% 30$-day postoperative incidence of hematoma in primary augmentation or delayed tissue expander based breast reconstructions.

OBJECTIVE: To determine the incidence of postoperative bleeding complications associated with preoperative administration of 5000 units of subcutaneous heparin and compare that incidence with previously published data. METHODS: Patient data were collected prospectively and maintained in a secure database at a single institution with institutional review board approval. Current procedural terminology and International Classification of Diseases, Ninth Revision, coding was then used to identify all patients who received either primary breast augmentation or delayed tissue expander based breast reconstruction during a five-year period. The primary outcome was the incidence of postoperative bleeding complication. A bleeding complication was defined as any hemorrhagic event that required a return to the operating room. RESULTS: The overall incidence of significant postoperative bleeding was $1.47 \%$ (five of 340 [1.16\% augmentation, $2.50 \%$ expander]). Comparing the current results with the previously published data, demonstrated an OR of 0.98 (95\% CI 0.38 to 2.55).

CONCLUSION: In women undergoing primary breast augmentation or delayed tissue expander breast reconstruction, heparin prophylaxis did not increase the risk for significant postoperative bleeding compared with historical controls.

Key Words: Breast implant; Chemoprophylaxis; DVT; Hematoma; SCIP

T here is often a delicate balance between the risks and benefits of medical intervention. The surgeon is obliged to not only be up to date on the evidence-based medicine for the intervention, but also knowledgeable of current regional and national guidelines to determine whether a preventive measure warrants use. Thromboembolic events are one of the well-known risks of surgical intervention. Both the American College of Chest Physicians and Surgical Care Improvement Project guidelines mandate both mechanical and medical perioperative thromboembolic prophylaxis in surgical patients and any exceptions to the use of these measures must be documented (1). However, the benefits of chemoprophylaxis may not outweigh risks in low-risk plastic surgery patients. The Caprini Risk Assessment Model is the most widely known risk stratification model and, while it offers a means to stratify surgical patients based on risk, it is not used to determine whether patients require chemoprophylaxis or could safely have mechanical prophylaxis alone (2). In 2008, the

\begin{abstract}
L'héparine préopératoire accroît-elle le risque d'hémorragie postopératoire chez les femmes qui reçoivent un implant mammaire? Une analyse de données monocentriques
\end{abstract}

\begin{abstract}
HISTORIQUE : En 2008, l'établissement des auteurs a adopté une politique selon laquelle toutes les patientes, quel que soit leur risque préopératoire, reçoivent à la fois des appareils de compression séquentielle et une unique injection préopératoire de 5000 unités d'héparine sous-cutanée. La publication d'une analyse sur 12 ans réalisée au même établissement avant l'adoption de cette politique démontrait une incidence postopératoire d'hématomes de 1,5\% au bout de 30 jours après une augmentation mammaire primaire ou une reconstruction mammaire tardive avec expandeurs tissulaires.

OBJECTIF : Déterminer l'incidence de complications hémorragiques postopératoires associées à l'administration préopératoire de 5000 unités d'héparine sous-cutanée et la comparer aux données publiées.

MÉTHODOLOGIE : Avec l'approbation du comité d'étude de l'établissement, les auteurs ont procédé à la collecte prospective des données des patientes et les ont conservées dans une base de données monocentriques sécurisée. Ils ont ensuite utilisé la terminologie à jour des interventions et les codes de la Classification statistique internationale des maladies, Neuvième révision pour déterminer, sur une période de cinq ans, toutes les patientes qui avaient subi une augmentation mammaire primaire ou une reconstruction mammaire tardive avec expandeurs tissulaires. Les résultats primaires étaient l'incidence de complication hémorragique postopératoire. Une complication hémorragique désignait tout événement hémorragique nécessitant une nouvelle opération.

RÉSULTATS : L'incidence globale de grave hémorragie postopératoire était de $1,47 \%$ (cinq cas sur 340 [1,16 \% après l'augmentation, 2,50 \% après l'expansion]). La comparaison des résultats récents avec les données publiées a démontré un rapport de cotes de 0,98 (95\% IC 0,38 à 2,55).

CONCLUSION : Chez les femmes qui subissent une augmentation mammaire primaire ou une reconstruction mammaire tardive avec expandeurs tissulaires, la prophylaxie à l'héparine n'accroissait pas le risque de grave hémorragie postopératoire par rapport aux sujets témoins rétrospectifs.
\end{abstract}

division of plastic surgery adopted an all-in policy in which every patient undergoing surgery under a general anesthetic would receive both sequential compression devices initiated before induction of anesthesia and 5000 units of subcutaneous heparin. It was the goal of the present study to examine the use of chemoprophylaxis and determine whether the bleeding risk was in concordance with previously published data.

\section{METHODS}

Beginning in 2008, patient data were collected prospectively and maintained in a secure database at a single institution with institutional review board approval. Current procedural terminology and International Classification of Diseases, Ninth Revision coding was then used to identify all patients who underwent either primary breast augmentation or delayed tissue expander based breast reconstruction during a five-year period from January 2008 to December 2012. The primary outcome

Division of Plastic Surgery, Department of Surgery, Baylor, Scott and White and Texas AEM Health Sciences Center College of Medicine,

Temple, Texas

Correspondence: Dr Raman C Mahabir, Mayo Clinic Hospital clo Plastic Surgery, 5777 East Mayo Boulevard, Phoenix, Arizona 85054, USA.

Telephone 480-342-1379, fax 480-342-2899, e-mail mahabir.raman@mayo.org 
was the incidence of postoperative bleeding complication. A bleeding complication was defined as any hemorrhagic event that occurred postoperatively and required a return to the operating room.

\section{RESULTS}

There were 340 cases reviewed with 100\% 30-day follow-up data. Of those, $260(76.47 \%)$ were breast implants and 80 (23.52\%) were delayed tissue expanders. The incidence of a bleeding complication necessitating return to the operating room was $1.47 \%(n=5)$ : three augments (21.4\%); and two delayed tissue expanders (2.5\%).

Comparing the current results with the previously published data demonstrated an OR of 0.98 (95\% CI 0.38 to 2.55 ).

\section{DISCUSSION}

Perioperative deep vein thrombosis (DVT) prophylaxis became a part of conventional practice among surgeons in 2008, following the review of medical data by the United States government (1). It has become so commonplace that often surgeons do not question whether it is always appropriate. There are surgeons, however, who debate the benefit of anticoagulation in low-risk surgeries and do not agree with its universal administration. While large operations, such as free flap reconstructions, carry a significantly increased risk for thromboembolic events, not all surgeries or patients carry the same risk. The current study demonstrated that heparin prophylaxis did not increase the risk for significant postoperative bleeding compared with historical controls in women undergoing low-risk breast surgery.

The Caprini Risk Assessment Model is a well-researched tool for risk stratification to determine a patient's relative risk for developing a DVT (2). It provides a checklist with risk factors broken into separate groups in which each risk factor is assigned a numerical value of 1 through 5 . The patient's risk factors are totalled and the higher the number the more at risk the patient is for a thromboembolic event. While it is a valuable tool, it does have limitations. One limiting factor of the Caprini Risk Assessment Model is that it states any patient with a score of 0 to 2 is a candidate for early postoperative ambulation alone (ie, no medical or mechanical prophylaxis). This is at odds with current national guidelines. A second limiting factor is that while the Caprini model has been validated in multiple studies, the length of time it takes to complete the survey may reduce the likelihood of physician utilization. Given these facts, it would be ideal if there were a safe universal preoperative policy that was applicable to both high- and low-risk patients.

In 2008, our institution adopted a policy requiring all patients, regardless of preoperative risk, receive both sequential devices and a single preoperative 5000 unit injection of heparin. A previously published 12-year review at this same institution before this policy demonstrated a $1.5 \% 30$-day postoperative incidence of hematoma in primary augmentation or delayed tissue expander based breast reconstructions (3). Our current results indicate that heparin prophylaxis carries an acceptable risk and, in fact, the risk of significant postoperative bleeding was unchanged. Ultimately, a thorough history and physical are paramount to optimal patient care and risk stratification; however, it is important to note that universal anticoagulation does not appear to carry significant risk.

Thromboembolic risk factors are cumulative, meaning each additional risk factor significantly increases the likelihood of a postoperative venous thromboembolic event (VTE) (4). There is ample evidence revealing the importance of chemoprophylaxis in higher risk patient populations, as VTEs are serious, life-threatening complications (5). The evidence for the best practice for lower-risk patients, specifically Caprini scores $<3$, is scarce and less clear cut. For example, in a young healthy woman undergoing an elective 45 min breast augmentation whose only risk factors are surgery and oral contraception (Caprini score 2), should you give heparin prophylaxis?

Panucci et al showed patients with the highest Caprini Risk scores had the highest postoperative risk (6-9). Their review of data showed historical control rate of DVT in low-risk patients without prophylaxis was $1.69 \%$. Our postoperative bleeding complication rate was $1.47 \%$ highlighting that the risk of a DVT appears to be slightly higher than a postoperative hematoma.

Finally, the timing of chemoprophylaxis has been examined and whether it is given pre- or postoperatively was not found to make a significant difference in complication rates and, therefore, we recommend it be given preoperatively to be in compliance with national guidelines $(9-10)$. The postoperative hematoma rate in previous studies $(4.5 \%$ [9] and 3.4\% [10]) was similar to our review (1.5\%), and we believe, as did the authors of those studies, that this is an acceptable risk given the benefit of risk reduction for venous thromboembolism.

The present study was a single-centre review and, as such, the results may not be generalizable to other surgeons, patient populations, institutions or geographical locations. A large multicentre trial would be the next step in answering this question more definitively. We hope that the present study will serve as a stimulus to surgeons to consider participating in such a study.

\section{CONCLUSION}

A prospective review of a single institution, in which all women, regardless of preoperative risk, received heparin chemoprophylaxis for implant surgery demonstrated a $1.47 \%$ risk of a significant bleeding complication defined as needing an urgent operative intervention. Preoperative heparin VTE prophylaxis did not pose an increased risk for complication compared with previous data without heparin.

DISCLOSURES: The authors have no financial disclosures or conflicts of interest to declare.

AUTHOR CONTRIBUTIONS: Sharon E Monsivais MD: study design, data collection/analysis and manuscript writing; Kendall $\mathrm{R}$ Roehl MD: study design, data analysis and manuscript editing; Raman C Mahabir MD MSc: original concept, study design, data analysis and manuscript editing.

\section{REFERENCES}

1. "Surgical Care Improvement Project." The Joint Commission. N.p., n.d. Web. 27 Feb. 2014: Specifications Manual for National Hospital Inpatient Quality Measures Discharges 01-01-14 (1Q14) through 09-30-14 (3Q14).

2. Wilkins EG, Pannucci CJ, Bailey SH, et al. Report on the PSEF thromboembolism prevention study: Validation of the Caprini Risk Assessment Model in plastic and reconstructive surgery patients. Plast Reconstr Surg 2010;126:107-8.

3. Collins JB, Verheyden CN. Incidence of breast hematomas after placement of breast prosthesis. Plast Reconstr Surg 2012;129:413e-420e.

4. Hight, H. SCIP: A National Quality Partnership. Venous thromboembolism \& prophylaxis in the surgical patient. US Department of Health and Human Services, 2011.

5. Motykie GD, Zebala LP, Caprini JA, et al. A guide to venous thromboembolism risk factor assessment. J Thromb Thrombolysis 2000;9:253-62.

6. Pannucci CJ, Laird S, Dimick JB, et al. A validated risk model to predict 90-day VTE in postsurgical patients. Am Coll Chest Phys 2013 (E-pub ahead of print).

7. Pannucci CJ, Bailey SH, Dreszer G, et al. Validation of the Caprini Risk Assessment Model in plastic and reconstructive surgery patients. J Am Coll Surg 2010;212:105-13.

8. Pannucci CJ, Fischer Wachtman C, Dreszer G, et al. The effect of postoperative enoxaparin on risk for re-operative hematoma. Plast Reconstr Surg 2012;129:160-8.

9. Keith JN, Chong TW, Davar D, Moore AG, et al. The timing of preoperative prophylactic low-molecular-weight heparin administration in breast reconstruction. Plast Reconstr Surg 2013;132:279-84.

10. Collins JB, Verheyden CN, Mahabir RC. Core measures: Implications for plastic surgery. Plast Reconstr Surg 2013;131:1266-71. 